\title{
Avosidade x maternidade: a avó como suporte parental na adolescência
}

\author{
Kelly Lins Beserra Pinto - Universidade Católica de Brasilia, Brasilia, Brasil \\ Alessandra da Rocha Arrais - Universidade Católica de Brasilia, Brasilia, Brasil \\ Katia Cristina Tarouquella Rodrigues Brasil - Universidade Católica de Brasilia, Brasilia, Brasil
}

\begin{abstract}
Resumo
Trata-se de um estudo de caso cujo objetivo foi identificar e discutir o lugar da avó como apoio parental para uma paciente adolescente de 15 anos. Baseou-se nos relatos das sessões de psicoterapia, que revelaram o desamparo da adolescente diante da falta de uma rede de proteção social e institucional e apontou a fragilidade materna em resistir a destrutividade que os atos da adolescente lhe impunha. Constatou-se que a avó ocupou um lugar de suporte afetivo para essa adolescente já que sua mãe tinha dificuldades em exercer seu papel parental. A adolescente na psicoterapia pôde perlaborar os desafios relacionais com sua mãe e com a avó. Hipotetiza-se se as transgressões desta adolescente são de significação consciente ou inconsciente que se relacionam à busca de limites e de reconhecimento direcionados a essas duas figuras femininas. O processo psicoterápico permitiu que a adolescente experimentasse seus desafios pulsionais, sem se sentir ameaçada ou invadida por eles.
\end{abstract}

Palavras-chave: Adolescência, Avós, Apoio parental.

\section{Grandmotherhood $\mathrm{x}$ motherhood: the grandmother as parental support in adolescence}

\begin{abstract}
This is a case study aimed to identify and discuss the place of the grandmother as parental support for a 15-year-old patient. It was based on reports of their psychotherapy sessions, which showed the helplessness of the adolescents regarding the lack of a social safety net and institutional and pointed the mother's fragility to resist the acts of destructiveness imposed by her teenager. It was found that the grandmother occupied a place of emotional support for this teen as her mother had difficulties in exercising her parental role. The adolescent in psychotherapy could work challenges related to her mother and grandmother. It is hypothesized that adolescent transgression relates to conscious or unconscious signification that searches limits and directed the recognition of these two female figures. The psychotherapeutic process allowed this teen to experience her instinctual challenges, without feeling threatened or invaded by them.
\end{abstract}

Keywords: Adolescence, Grandparents, Parental support.

\section{Abuelidad x maternidad: la abuela como apoyo parental en la adolescencia}

\begin{abstract}
Resumen
Se trata de un estudio de caso que tuvo como objetivo identificar y discutir el lugar de la abuela como apoyo de los padres de una paciente de 15 años. Se basa en los informes de las sesiones de psicoterapia, que revelan el desamparo de la adolescente frente a la falta de una red de protección social e institucional y apunta la fragilidad materna para resistir a la destructividad que los actos de la adolescente le imponían. Se encontró que la abuela ocupaba un lugar de soporte emocional para esa adolescente puesto que su madre tenía dificultades para ejercer su rol parental. La adolescente pudo tener la perbaboración de los problemas relacionales con su madre y su abuela en la psicoterapia. Se hipotetiza si las transgresiones de esa adolescente son de significado consciente o inconsciente y se relacionan con la búsqueda de límites y de reconocimiento dirigidos a esas dos figuras femeninas. El proceso psicoterápico permitió que la adolescente experimentase sus desafíos instintivos sin sentirse amenazada o invadida por ellos. Palabras clave: Adolescencia, Abuelos, Apoyo parental.
\end{abstract}

\section{Introdução}

Estudos apontam que, com os novos arranjos, a composição das famílias brasileiras ganhou força expressiva dos idosos (Debert \& Simões, 2006; Dias, 1994; Goldfarb \& Lopes, 2006, Lima, de Moraes \& Augusto Filho, 2008). Diante do aumento da longevidade, os idosos passaram não só a conviver mais tempo com seus descendentes, bem como passaram a exercer diferentes papéis na dinâmica familiar e a velhice passou a ocupar um novo lugar. Apesar da ideia de exclusão e de fragilidade associadas à velhice, além do apoio financeiro, o idoso pode ser uma figura de referencia parental tanto para seus filhos como para seus netos (Oliveira, 2011).

Para conviver com as gerações mais novas, os avós desenvolveram estratégias relacionais de convivência com outras gerações, entre elas, a abertura para novas experiências. Diante das particularidades da dinâmica familiar, alguns avós desempenharam a função de cuidadores, prestando apoio afetivo e financeiro à rede familiar, enquanto outros assumiram a função paterna ou materna somando os papéis de avós e pais dos netos (Oliveira, 2011; Vitale, 2008). 
Reconhecendo os novos laços que se constituem entre os adolescentes e seus pais e avós, este estudo buscou identificar e discutir o modo de relação estabelecido entre uma adolescente e sua avó, tendo em vista a fragilização da função parental, pela ausência materna e paterna. Embora existam pesquisas sobre a importância dos avós na infância, poucos estudos abordam a função destes e sua relevância na adolescência dos netos.

\section{Adolescência e o apoio narcísico parental}

Segundo Pereira (2005), a palavra adolescência deriva do latim adollacentia, e significa processo de crescimento em direção à maturidade. Marty (2006a) teoriza que esse movimento maturacional acontece com o início do pubertário, momento do redespertar dos conflitos edipianos da primeira infância. Freud (1905/2001), um dos pioneiros no estudo da adolescência, destaca que, nesse momento, o sujeito redireciona a libido, afrouxando os laços com a família, que foram decisivos na infância. Há um amadurecimento do aparelho genital com desenvolvimento da função reprodutora e o sujeito se percebe capaz de gerar outros indivíduos, aspectos que podem parecer ameaçadores aos privilégios da infância, bem como sedutores diante da possibilidade de usufruir, sem responsabilidades, do gozo genital.

Nesse processo de transição, Marty e Cardoso (2008) ressaltam que o adolescer não se limita ao movimento de extensão da infância, que tornará o sujeito homem ou mulher; na verdade, ao reviver a problemática edipiana infantil, ele se depara com as transformações corporais e a necessidade de integrá-las sem se perder em meio à crise "mudar e permanecer $\mathrm{o}$ mesmo" (Marty \& Cardoso, 2008, p. 11).

Nesse trânsito crítico o jovem repudia as identificações da infância tentando se diferenciar dos valores estabelecidos pelos pais e pela cultura em um movimento de separação/ individuação. Todavia, também reconhece sua forte ligação com os objetos internos, ou seja, seu pertencimento, pela compreensão daquilo que apreendeu sobre si na relação com seu meio familiar e sociocultural, nos explica Pereira (2005).

Nesse contexto, as mudanças psíquicas produzidas com a entrada na puberdade confrontam o adolescente exigindo a reorganização e reestruturação da sua identidade. $\mathrm{O}$ medo das mudanças individuais, culturais e sociais, e a angústia de ter que se assegurar no mundo externo caminham juntos no processo de adolescer (Savietto \& Cardoso, 2006). Esse processo sinaliza que o jovem precisará de sólidas bases narcísicas, portanto, se as relações objetais primárias forem insuficientes para fornecer ao sujeito uma solidificação narcísica no momento da adolescência, as falhas narcísicas serão incontornáveis (Savietto \& Cardoso, 2006).

Assim, no contexto da adolescência os adultos serão particularmente solicitados, pois terão que ajudar os adolescentes a enfrentarem no real do corpo as visíveis modificações, bem como exercerem a função de paraexcitação, de continente, daquilo que no sujeito adolescente esteja transbordante, afirma Marty (2006b).

Contudo, os adolescentes podem não encontrar a sua volta um apoio parental que possa sustentar a posição de suporte e de continente para o desafio pubertário, pelo contrário, alguns adolescentes enfrentarão sozinhos esse período, e essa situação poderá complexar sobremaneira esse momento da vida.

$\mathrm{O}$ apoio narcísico parental se refere à sustentação advinda dos adultos no momento em que o adolescente se encontra em situação de fragilidade narcísica ou se percebe desamparado. Nesse período de crise, o apoio parental oferece ao sujeito bases para que no momento da reorganização identificatória, na adolescência, ele escolha novos objetos para investir e dar continuidade ao desenvolvimento de forma criativa a serviço da vida (Marty, 2006b).

De modo que a ausência do apoio narcísico parental leva os adolescentes a recorrer aos acting outs ou atos direcionados a si mesmo ou ao outro. No entanto, os adultos podem sentir-se desamparados ante o desafio de enfrentar a violência do pubertário. Assim, alguns pais, segundo Marty (2006a), desconhecem as formas de proteger os próprios filhos da violência contra si mesmos ou não conseguem resistir a destrutividade do filho, de modo que a fragilidade dos adultos não contribui para que os adolescentes encontrem o apoio narcísico parental para enfrentar algo de si mesmo que lhe escapa.

\section{Avosidade $\times$ parentalidade}

A literatura aponta (Berger, 2003; Goldfarb \& Lopes, 2006) que a modificação no papel dos idosos no contexto familiar e social provocou uma crise de identidade na avosidade. A definição desse termo difundiu-se com os estudos de Paulina Redler, no ano de 1977, sobre psicogerontologia. Estes sugeriam ampliação da visão biológica para além da idade cronológica ao realçar os laços de parentesco que exigem do idoso a reestruturação psíquica ao ocupar um novo status pessoal, psíquico, familiar e social: ser avô/avó (Pedrosa 2006).

Contudo, para Goldfarb e Lopes (2006), o que definirá a avosidade não será a idade cronológica ou o 
papel social, mas a possibilidade de transmitir as funções materna e paterna para as próximas gerações. Tornar-se avô requer uma elaboração do próprio papel como filho e pai, pois o nascimento de um neto exige uma reorganização psíquica. Agora, ele ocupará um novo lugar, será preciso demarcar os limites entre ser avô e pai para passar pelo processo de individuação na estrutura familiar.

A chegada de um neto para a mulher de meia-idade pode oferecer uma nova oportunidade para viver a experiência da maternidade, em forma de autorrealização emocional, mas também pode provocar desconforto e desapontamento colocando-a em confronto com a realidade, forçando-a a pensar na idade e na proximidade da morte (Dias, 1994). Apesar disso, ser avó na contemporaneidade aponta para novas posições nas relações na família e no contexto social. Rodrigues e Justo (2009) chamam atenção para os novos papéis desempenhados pelas avós, que podem ser ao mesmo tempo mães e avós zelosas, mas também mulheres maduras, sedutoras e ativas.

Oliveira (2011) apresenta ainda a classificação atual sobre o estilo dos avós de Gauthier: o "encarregado", que são os avós que cuidam dos netos, substituindo em vários momentos os pais da criança; o "especialista", que são os avós que dispõem de menos tempo e participam de apenas algumas esferas na vida dos netos e se especializam nelas e os avós "passivos" que são aqueles que convivem pouco com os netos, que são os quase-ausentes, por residirem em outra cidade, por exemplo, e os realmente ausentes, quando a relação com os netos nem existe. No Brasil, Debert e Simões (2006) observaram dois tipos específicos de arranjos familiares com a presença de idosos: as famílias de idosos e as famílias com idosos. A primeira considera a posição do idoso como chefe de família, sendo provedor financeiro na criação dos netos; enquanto na segunda, famílias com idosos, em especial as de baixa renda, seu papel é de suporte afetivo nos cuidados com as crianças, pois depende financeiramente dos filhos ou netos.

Nesse sentido, ocupar o lugar de avós exige destes o consentimento para que os seus filhos sejam pais para desempenhar o papel educativo e afetivo, cabendo aos pais, na posição de avós, permitirem que seus filhos assumam as funções parentais, ficando na posição de elo entre as gerações, sem, no entanto, se ausentar do seu lugar: ser avô/avó (Goldfarb \& Lopes, 2006). Os autores acrescentam, ainda, que o lugar e a função dos avós podem se confundir com dos verdadeiros depositários desses papéis, os pais, tendo em vista os desafios sociais e econômicos que as famílias contemporâneas enfrentam.

Contudo, para Lopes, Nery e Park (2005), o idoso pode passar pela experiência de ser avô sem se comprometer com obrigações maternas e paternas. Pode desenvolver novos vínculos com seus netos, permitindo que identificações sejam estabelecidas sem haver sobrecarga ou estresse. Nesse sentido, Vitale (2008) aponta que a maioria dos avós se dispõe voluntariamente a cuidar dos netos. Porém, isso não quer dizer que o tornar-se avô ofereça apenas vivências prazerosas. Enquanto alguns prestam cuidados quando são solicitados, outros se sentem obrigados a praticar essas ações por depender financeiramente dos filhos ou para cumprir um papel social esperado.

Sob esses aspectos, quando há ausência do pai e da mãe, os avós tendem a desempenhar as funções parentais como pais substitutos. De acordo com Oliveira (2011), é notório o aumento do estilo de pais substitutos em todo o mundo. Com seus papéis expandidos, podem encontrar satisfação ao oferecer benefícios aos netos, ou também, ônus com o estresse físico e emocional. Apesar dos efeitos negativos, Oliveira (2011) alerta que dificilmente os avós recusam a tarefa de cuidar dos netos, pois o compromisso que percebem ter com sua descendência faz com que eles se responsabilizem pela prole de seus filhos, ainda que haja alguma perda para suas próprias vidas cotidianas.

Nota-se que a literatura deixa evidente que a entrada na avosidade estaria relacionada a uma preparação e elaboração dos estágios anteriores para o exercício desse papel. No entanto, o levantamento teórico denuncia uma marca cristalizada na qual os autores percebem os avós como cuidadores ou figuras de apoio idealizado durante a infância dos netos, desconsiderando a possibilidade de emergirem outros sentimentos humanos, durante essa fase, nas relações entre avós e netos.

Deposita-se a expectativa do exercício de uma avosidade desprovida de ambivalência e realizada por pessoas perfeitas e em condições ideais, aspectos que distanciam a possibilidade de existirem sentimentos conflituosos na condição de tornar-se avô. Molinier (2004), ao contrário da maioria dos estudos, discute a ambivalência e a flutuação de sentimentos contidos no cuidado com o outro. A autora destaca que o cuidado ou a preocupação com outro implica trabalho, o qual pode mobilizar sentimentos duvidosos de amor e ódio.

O envelhecimento, apesar dos ganhos da modernidade, carrega também as contradições de uma sociedade que mantém os adultos em posições infantilizadas e 
com grandes dificuldades em assumir seus lugares de pais. Nesse cenário, os avós podem assumir o lugar parental quando os pais falham nessa função. Nessa perspectiva, este trabalho pretende identificar a vivência de uma adolescente cuja mãe falha em assumir seu lugar parental, cabendo à avó o lugar de apoio narcísico parental.

O caso que será apresentado nos oferece duas relações de mãe-filha, a relação da adolescente Clara e sua mãe e a relação da mãe de Clara com sua avó. A relação mãe e filha recebe uma atenção particular na psicanálise, quando Freud (1925/1976; 1931/1974) assinala a mãe como primeiro objeto de amor para a menina e ressalta a intensidade desse vínculo primário, vínculo este que se fragiliza pelo impacto da castração. O complexo de castração revela para a menina, por meio da percepção das diferenças anatômicas entre meninos e meninas, um sentimento de inferioridade e de injustiça. Posteriormente, na adolescência, segundo Emmanuelli (2011), a questão que é colocada se refere ao trabalho psíquico da elaboração do Édipo, do narcisismo e da problemática da separação e da identificação entre mãe e filha, que serão tratados neste trabalho.

Assim, a questão que não se pode deixar de discutir se refere ao lugar da relação entre mãe e filha, que atravessa duas gerações, ou seja, a primeira geração que se refere à mãe da adolescente e sua própria mãe, a avó de Clara, e a outra geração, que se refere à adolescente Clara e sua mãe, relação esta intermediada pela avó. A relação entre mãe e filha de duas gerações pode ser uma devastação para essas mulheres, pois é uma relação que se apresenta pela (im)possibilidade desse amor (Lacan, 1973/2003). Os desafios da maternidade, segundo Marcos (2011), passa pelo registro fálico, pela compreensão, na menina, de que a mãe é aquela que tem o falo; essa situação marca a ambivalência que funda essa relação, que é caracterizada pelo lugar da mãe como primeiro Outro íntimo e estrangeiro do qual é preciso se separar, movimento que demanda um importante trabalho psíquico para as meninas no processo de construção de sua feminilidade a partir da relação com sua mãe.

\section{O lugar dos avós diante da falha parental}

De acordo com Sarti (2008), para a família manter seu equilíbrio, ela se desdobra em relações complexas para atender às demandas que vão surgindo. Pode ocorrer do status atual de um membro não corresponder ao seu papel convencional, divergindo da função que deveria ser exercida. Por exemplo, há casos em que a mãe permanece presa ao papel de filha e não consegue exercer a função materna, comportando-se como uma "irmã mais velha" do filho, delegando a função materna à avó. Esses avós, segundo Goldfarb e Lopes (2006), permitem que a criança e o adolescente vivam seu lugar filial em um tempo provisório; no entanto, esse funcionamento cria um dilema para a criança sobre os verdadeiros depositários desses papéis.

Como visto anteriormente, as próprias condições internas e externas vividas durante a adolescência impulsionam o adolescente a solicitar dos adultos a continência, orientação, controle e limites diante da violência do próprio período. Marty $(2006 a, 2013)$ ressalta que diante da ausência ou falha parental, referida neste trabalho como falta de apoio afetivo dos cuidadores, nas novas configurações familiares, os avós podem ser as novas figuras parentais que oferecem aos adolescentes o apoio narcísico parental para resistirem e não sucumbirem aos impulsos destrutivos que emergem no período pubertário (Goldfarb \& Lopes, 2006; Marty, 2006a, 2013).

As falhas parentais se constituirão quando os pais não conseguem realizar a operação simbólica das funções paterna e materna para que a criança estabeleça as identificações primárias que asseguram a continuidade do ser, esclarecem Lopes e Goldfarb (2006). Entretanto, com as mudanças nos laços familiares, a figura dos avós ganha destaque na contemporaneidade, pois estabelecem relações afetivas com os netos ante a instabilidade psicossocial e econômica que atinge as famílias (Oliveira, 2011).

Assim, os avós participam ativamente e desempenham outros papéis na relação afetiva com os netos. Eles se dispõem a cuidar dos netos, conciliando ou sobrepondo as responsabilidades de mulher/homem, mãe/pai e avó/avô no exercício de suporte à família (Vitale, 2008). Para alguns, o lugar de avós não está bem delimitado, porque não conseguem se separar e transformar a relação com o filho, agora pai, integrando o novo membro, o neto, à família no status de neto e não de filho. $\mathrm{Na}$ atualidade, diante da nova ordem familiar que se estrutura, tal dimensão traz o questionamento sobre qual lugar os avós estariam ocupando nas famílias. Estariam estes vivendo o tempo de serem pais ou verdadeiramente avós dos netos?

\section{Objetivo geral}

Compreender as peculiaridades e dificuldades vivenciadas por uma adolescente que, em busca do apoio narcísico parental, solicita dos avós o amparo 
afetivo para suportar as mudanças que o processo da adolescência lhe impõe.

\section{Método}

Este artigo trata-se de um estudo de caso qualitativo que se desenvolveu a partir do atendimento psicoterápico breve com orientação psicanalítica de uma adolescente, 15 anos, do sexo feminino, estudante do ensino médio de uma escola pública do Distrito Federal. Na Psicanálise, o estudo de caso é uma estratégia metodológica na clínica. Esse método é entendido como resultado de uma experiência vivida na clínica psicanalítica e que, ao dialogar com a teoria, torna-se um caso construído e comunicado (Moura \& Nikos, 2000). Será a partir do analista-pesquisador que se escolherá um fragmento do tratamento para análise e teorização. O trabalho seguiu rigorosamente os procedimentos éticos e legais recomendados pelas resoluções vigentes referentes às Clínicas-Escola, onde o paciente, ao ingressar no tratamento, autoriza por escrito, em termo de compromisso, que as informações provenientes dos atendimentos podem ser utilizadas para fins de ensino e pesquisa, assegurados o sigilo profissional, a não identificação do usuário e seu bem estar e privacidade.

A adolescente que protagoniza o caso clínico, a qual chamaremos de Clara (nome fictício), foi encaminhada para o atendimento psicoterápico em nossa clínica escola pelo Conselho Tutelar de sua cidade. Foi atendida individualmente, em sessões semanais, com duração de 50 minutos cada, entre o primeiro semestre de 2009 e o segundo semestre de 2010, totalizando 20 sessões, que foram todas relatadas por escrito, no prontuário da paciente. A terapeuta, que é a primeira autora deste artigo, era na época estagiária do último ano de psicologia e foi supervisionada pela $2^{\mathrm{a}}$ autora. Utilizou os relatos das sessões clínicas e as autoras procuraram analisar e interpretar os aspectos psicodinâmicos da adolescente e a dinâmica relacional dessa adolescente com sua mãe e com sua avó. Abordaram-se tanto os elementos que emergiram das sessões quanto aqueles que emergiram das entrevistas com a mãe e a avó de Clara, pois ambas foram ouvidas durante o acompanhamento psicoterápico de Clara. A análise do material das entrevistas e das sessões psicoterápicas de Clara se apoiou na abordagem clínico-qualitativa, tendo como embasamento teórico a Psicanálise e a Psicogerontologia, que possibilitou a organização e interpretação do material clínico.

Consideraram-se os aspectos conscientes e inconscientes que regem o processo da adolescência no círculo de convivência, com a mãe e os avós, para compreensão do modo de se relacionar da jovem. Inspirando-se no método adotado por Conti (2004), optou-se por limitar o material registrado nas sessões clínicas a dois blocos de informações: 1) o caso Clara: contexto clínico e familiar; 2) análise interpretativa do caso.

\section{Resultados e Discussão}

\section{O caso Clara: contexto clínico e familiar}

Clara chegou à terapia acompanhada da avó materna, com quem morava e a qual assumia o papel de adulto responsável na ausência da mãe, que trabalhava em tempo integral. Clara apresentou-se bem tímida no primeiro dia, talvez porque estivesse diante de sua avó, uma figura que lhe impunha autoridade e respeito. $\mathrm{O}$ jeito de se vestir da adolescente era calça jeans, mochila e All Star, usava um lenço de caveira e uma blusa de banda de rock. Durante a primeira entrevista, Clara limitou-se a ser monossilábica, dizendo não se sentir à vontade para falar de suas intimidades diante da avó.

A sós com a adolescente, ela justificou o porquê dos comportamentos ousados e transgressivos. Foram estes, segundo a jovem, motivados por um amor erótico quase obsessivo por uma professora, que a levaram a ser encaminhada ao Conselho Tutelar. Além do ressentimento em relação à professora, por não corresponder às suas investidas amorosas, Clara também se queixou da falta de compreensão da escola e da família quanto a sua necessidade de estar ao lado dessa professora, expressos nas seguintes falas: "é mais forte do que eu... fico atrás das pilastras... pulei o muro só para ficar olhando para ela"

No espaço psicoterápico, Clara teve posições regredidas em relação á psicoterapeuta e atuadas de modo a transgredir o setting psicoterápico, como um modo de ataque ao enquadre. O movimento transferencial de Clara no processo psicoterápico indicava que ela tinha dúvidas se a psicoterapeuta seria capaz de conter e resistir a sua destrutividade adolescente.

Contudo, os desafios da adolescência puderam ser trabalhados nas sessões e Clara pôde abordar a dor de ter que abandonar os privilégios da infância e responsabilizar-se pelas próprias ações, agora que caminhava rumo à vida adulta. Certa vez, quando falava dessa angústia, relatou: "falar em ser adulto é como se estivesse enfiando agulhas em mim... Tenho vontade de gritar". No completamento de frases, colocou: "adolescência é a pior coisa que Deus me presenteou".

Clara residia com a mãe (37 anos), caixa de supermercado; a avó materna (60 anos), dona de casa; e a 
irmã (11 anos), estudante. O avô materno (62), funcionário público aposentado, de quem recebia auxílio financeiro, morava em outra cidade.

Ao construir o desenho da linha da vida, Clara trouxe alguns elementos da sua história familiar e o modo como ela nasceu. Ela relatou que o encontro dos pais e seu nascimento foram resultado do encontro sexual de seus pais de apenas uma noite. Clara parecia lamentar esse fato e sobre isso ela falou: "gostaria de ter uma família tradicional", e com sofrimento destacou o distanciamento do pai durante a gravidez de sua mãe, representado no desenho por uma figura masculina que corria da mãe, a qual sinalizava com os braços para que este voltasse.

A ausência do pai foi descrita como dolorosa pela jovem, que conviveu com a imagem de um homem que fugira da mãe e, consequentemente, dela. Verbalizou sentir falta de uma figura paterna. Quando criança, os colegas de turma perguntavam sobre seu pai, e ela dizia não saber deste. A entrevista clínica com a mãe confirmou a ausência paterna e a dificuldade de Clara em lidar com essa falta, e ela mencionou que a filha se isolava na escola quando outras crianças a questionavam sobre a ausência do pai.

A mãe de Clara, uma jovem franzina, aparentando ter menos de 30 anos e que parecia uma irmã mais velha de Clara, mostrou-se preocupada com as ações transgressivas que a filha vinha tomando, que acarretaram no afastamento da escola. Abordou também sobre suas dificuldades em conversar com Clara. Sua fala refletia o estranhamento dessa mãe frente à adolescência de uma filha que, na infância, havia sido estudiosa e interessada na escola, e sobre isto relatou: "de uns tempos para cá as coisas pioraram". A mãe de Clara, que investe atualmente em um relacionamento amoroso, encontra resistência de Clara, que relata que a mãe fica mais afastada dela, pois dorme na casa do namorado nos finais de semana. Sobre o afastamento da mãe, Clara disse: "eu só queria que minha mãe ficasse mais em casa".

Clara faz uma demanda de amor à sua mãe, que desvia seu olhar de Clara e o deposita em um outro objeto de amor, o novo companheiro. Essa demanda de amor de Clara seria uma busca infinita de substância, sem limite e que aproxima amor e devastação (Marcos, 2011). Segundo Lacan (1973/2003,) há uma expectativa da menina em relação à sua mãe que não se situaria somente sob o significante do falo e que ele nomeia como ravage, traduzido por devastação. Marcos (2011) lembra que, para a mulher, o amor se inscreve no imperativo de que o Outro a ame e assim diga do significante do seu ser, de modo que, na demanda de amor endereçada a sua mãe, Clara espera receber dela a substância do seu ser.

Clara é criada em uma casa onde imperou a ordem e autoridade feminina, em especial da avó materna, uma vez que a mãe assume o lugar de irmã mais velha delegando a sua mãe a encargo de criar Clara. É importante considerar também que, provavelmente, a mãe de Clara não podia assumir sua maternidade, em razão da sua posição subjetiva em relação à sua própria mãe, uma vez que é a avó de Clara que a substitui na função materna. Ou seja, o fato da mãe de Clara não poder assumir seu lugar de mãe perante a filha parece denunciar a impossibilidade dessa mulher sair do seu lugar de filha em relação à sua mãe, agora na posição de avó. Essa posição de poder da avó, aceita na prática pela mãe da paciente por esta leva a questionar a relação de poder transgeracional entre elas. $\mathrm{O}$ suporte indicado na discussão do caso pode também ser lido, portanto, como devastação entre mãe e filha, da qual nos fala Lacan (1973/2003). Essa situação sugere que a avó de Clara não deixou espaço para que sua filha assumisse a maternidade da neta. Diante desse contexto familiar, cabe questionar qual seria a força e o poder que essa a avó possui nessa família. Não estariam eles relacionados também à ausência/falha do marido/pai nessa constituição familiar? Será que mais uma vez a história se repete, ou seja, tanto a Clara, como sua mãe, não tiveram o lugar paterno assegurado na dinâmica familiar. Clara nos dá pistas sobre a ausência de seu pai e de seu avô na vida familiar ao afirmar que sua casa é a casa das mulheres. A afirmação da adolescente mostra que o tipo de organização e de autoridade nessa família é exercido pelas mulheres e no caso dessa família, a avó é colocada no lugar de matriarca, situação que evidencia a exclusão da figura masculina nesse meio familiar. Assim, ter a avó como apoio narcísico parental poderá permitir à Clara uma identificação feminina constitutiva para sua subjetividade, de modo que futuramente ela possa vir a ser mãe, e não delegar a sua própria mãe essa função quanto tiver seus filhos e, assim, tenha chance de não repetir a história transgeracional (Goldfarb \& Lopes, 2006).

2 Análise interpretativa do caso: Iniciar-se-á o processo interpretativo apresentando-se e discutindo-se o papel da avó diante da falha parental

\subsection{Avosidade: tempo de ser mãe e não avó!}

Em entrevista com a avó, esta mencionou que criou a neta desde bebê. Ressaltou que sempre foi uma menina ótima, "mas de uns tempos para cá, 
enlouqueceram a neta e a filha". A avó reclamou da falta de apoio da filha no cuidado com a neta. Ela foi à escola da jovem verificar se esta estaria estudando e, para sua surpresa, a menina apresentava um alto índice de faltas. Comentou que o diretor da escola solicitou a presença da mãe da adolescente, mas, segundo a avó, esta não se preocupava com a filha desde que começou a se relacionar com um novo namorado. A ausência da mãe, na primeira entrevista reforçou a impressão de que a avó estaria exercendo a função materna na vida da jovem.

A convivência intensa com essa avó, parceira da mãe na criação da neta, deu a essa figura um novo lugar, com exigências afetivas diferentes daquelas encontradas nos avós tradicionais. A avó, que na infância das netas exercia a função materna e paterna, agora não conseguia lidar com as mudanças no ciclo familiar: pois a neta criança a quem um dia ofereceu seus cuidados maternos, agora era uma adolescente.Observou-se que perante a ausência parental, Clara buscou na avó o apoio para suportar a violência do pubertário, como destacou Marty (2006b).

A situação clínica descrita acima evidencia a função subjetiva dos lugares de filiação nessa família e aponta para o modo como essa função se transmite de modo repetido entre as gerações nessa família de mulheres (Gomes \& Zanetti, 2009). Assim, quando a avó disse que Clara e sua mãe enlouqueceram, ela faz uma alusão à relação identificatória entre Clara e sua mãe pela transmissão psíquica entre as gerações de funções impossíveis de serem assumidas. Portanto, diante da complexidade dos elementos inconscientes que circulam entre essas mulheres, Clara, por meio do suporte de sua avó poderia construir uma identidade que lhe permitisse assumir a função materna no futuro? Nos parece que a avó não conseguiu proporcionar a sua filha, mãe de Clara, um lugar que lhe assegurasse assumir a função de ser mãe, e há certamente o risco de que ela faça o mesmo com Clara.

Outro aspecto que evidenciou a ausência de alguém que fosse referência de função paterna para impor limites e exercer o controle educativo junto à adolescente, como traz a autora Sudbrack e cols., (2003), foi o fato de a avó ter comunicado ao Conselho Tutelar, sem o conhecimento da mãe, para que este exigisse dessa a responsabilização pelos atos da adolescente. Segundo a avó, sua ação foi uma maneira de tentar resolver a situação da neta, pois não sabia mais a quem recorrer.

A mesma situação também exemplifica o que Marty (2006b) apontou como desamparo vivido também pelos cuidadores dos adolescentes ao se depararem com a própria incapacidade de suportar a impulsividade e agressividade que seus filhos ou netos passam nesse período.

Observou-se que essa avó assume o lugar que Sarti (2008) nomeou de chefe de casa, pois cuida da casa e das netas, enquanto a filha trabalha fora. Aspecto referido nas seguintes falas da avó materna "eu luto com estas meninas desde bebê, quem criou fui eu... Elas sempre tiveram hora para tudo, comer, tomar banho... Elas me obedeciam... Hoje é tudo liberado para fazerem o que quiserem", atribuindo a causa da dificuldade em manter a autoridade com as netas à ausência da mãe. Enfatizou a sua dificuldade em oferecer limites à neta sem contrarreagir "a menina é sem limite, ela não tem hora para nada, ela está solta no mundo".

Nota-se que a avó se preocupa afetivamente com a neta, desempenhando a função parental como mãe substituta, em busca de manter o equilíbrio familiar. No entanto, não consegue exercer a função referida na dimensão simbólica, oferecendo continência e limites, como trazem Sudbrack e cols., (2003) e Marty (2006a).

Outro aspecto pontuado por autores como Berger (2003), Goldfarb e Lopes (2006), e reconhecido no caso Clara, é que as mudanças do processo de adolescer da neta provocam a reavaliação das questões subjetivas da avó. Essa mulher também se depara com a própria realidade, diante das mudanças no ciclo familiar, pois a neta agora é uma adolescente e ela está envelhecendo. A manifestação dos conflitos da neta, em plena adolescência, aciona as questões emocionais e subjetivas da avó, fazendo com que esta entre em contato com suas necessidades internas, percebidas nas seguintes falas: "hoje eu também quero sair, ficar na casa das minhas amigas e descansar... Mas tenho medo de dormir e acordar morta... Se não for eu na vida dessas meninas, eu não sei o que pode acontecer com elas". Pelas falas e comportamentos da avó de Clara, nota-se que esta se encontra em meio à crise ou conflito de ter que assumir um lugar de avó substituta materna, para cumprir um papel que the foi imposto socialmente, e o de ter que lidar com a dualidade pulsional e os desejos de viver a própria maturidade e enfrentar a chegada da morte sem maiores preocupações.

As reações da avó, ao exercer os cuidados como mãe substituta, trazem um sofrimento psíquico com o sobrecarga da função de cuidar, visto que a filha, agora mãe, se recusa ou não tem condições psíquicas de ocupar a função materna no período da adolescência de Clara. O estado ambivalente vivido pela avó nos fala de 
um desgaste emocional e físico, provocando a emersão do conflito sobre sua condição atual, e de sentimentos dúbios contidos no cuidar do outro, como apontou Molinier (2004). Essa mulher idosa se defronta com a flutuação dos próprios sentimentos, pois o prazer que teve ao cuidar da neta enquanto criança, reeditando sua maternagem ao ter uma "segunda chance" (Oliveira, 2011, p. 24), não lhe é permitido com a mesma, agora na fase da adolescência. Esta não lhe oferece mais o prazer do cuidado corporal, mas lhe exige o apoio afetivo e suportivo.

Por outro lado, Lachmann (2011) nos mostra que a chegada de um neto para a mulher de meia-idade, pode oferecer uma nova oportunidade para experienciar a maternidade, em forma de autorrealização emocional, e até aumentar a sua longevidade. No entanto, essa oportunidade de "reviver" a maternidade pode fazer com que a avó impeça ou boicote as iniciativas dos próprios filhos em assumir a função paterna/materna, pois teme reconhecer o seu crescimento e amadurecimento subjetivo, que implicariam um processo de diferenciação, de distanciamento sentido como a "perda" do filho. Por essa razão, seria desejável que, com a chegada dos netos, as avós se colocassem apenas como elo entre pais e filhos e não os substituindo. Assim, no desempenho da sua função, o avô cederia ao filho o lugar para reprodução da função paterna/ materna (Goldfarb \& Lopes, 2006).

\subsection{Sou um adolescente, mas não quero crescer!}

Outro conflito psíquico central nas vivências da adolescência de Clara era o seu medo de crescer. O temor de entrar para o mundo adulto refletia uma identificação com a mãe, que, resistindo assumir seu lugar como mãe, delegava a sua própria mãe a função que lhe era falha.

Certa vez fez um desenho de uma menina de cabelos curtos, roupa de adolescente e uma lata de cerveja em uma das mãos, que Clara afirmou ser ela, e ressaltou a ausência dos pés da menina ao atravessar um caminho cheio de espinhos. A menina continuaria andando nesse caminho de joelho, depois de quatro, sei lá, e ainda que lhe implantassem pés ou colocassem sapatos, ela continuaria machucando os pés com os espinhos e durante esse percurso ela enfrentou "tempestades" intensas e novos períodos turbulentos ainda viriam. Segundo Clara, a jovem perdeu os sapatos aos nove anos de idade, período marcado pelo início de um amor transferencial por uma professora, o qual foi nomeado por ela como sentimento materno misturado com atração física. O caminho a ser percorrido pela jovem do desenho terminaria no mar. Para Clara, o mar significava a morte, pois ela não sabia nadar.

Observou-se que Clara trouxe no desenho o impacto que um adolescente sofre, ao ser empurrado pelo próprio processo de crescimento biológico para um lugar que lhe exige a redefinição da própria imagem, diante da perda do corpo infantil e aquisição de outras características corporais adultas. Clara se encontrava na condição de ter que continuar caminhando, ou seja, consciência da continuidade, de crescimento. Nesse processo de amadurecimento mental e fisiológico, Clara também se deparou com o medo de se desfazer no meio desse caminho em busca de uma identidade, simbolizado no desenho com a perda dos pés e finalmente a morte no mar. $\mathrm{Na}$ análise do desenho se encontram elementos discutidos por Marty (2006a) e Marty e Cardoso (2008), como a ambivalência e descontroles vividos por Clara ao enfrentar as modificações e transformações corporais e psíquicas que lhe impõe a condição de ter que se separar dos laços estabelecidos na infância para reinvestir em novos objetos de identificação e desenvolver sua autonomia. Clara se encontra em uma situação fronteiriça, pois parece caminhar da vida infantil para vida adulta. Ao experimentar a perda da continuidade de si mesmo, percebe-se um movimento em busca de sua identidade, a jovem continuará andando de joelhos ou de quatro,... Até chegar ao mar.

Esse mesmo conflito para se reconhecer como adolescente foi expresso em outro momento de atendimento clínico. A jovem utilizou uma metáfora dos parques de diversões, observada na seguinte fala:

Antes en estava em um parque de diversões... Mas acabaram os ingressos e ele faliu. Estou no meio... No outro teriam amigos, brincadeiras e festas, mas estou do lado de fora... Não quero perder meu lado crianca, brinco sempre com men namorado como se fosse sua filha, com minha mãe e avó como se fosse uma criança. (Clara)

Clara, ao se perceber "no meio" de dois parques de diversões, parece vivenciar um "entre lugares", não conseguindo formar um senso de identidade pessoal.

Observa-se que a jovem se encontra em um período confuso, de contradições e ambivalente, que traz impresso o que Marty e Cardoso (2008) chamam de conflito entre a necessidade de manter o investimento narcísico, as heranças da infância, e a obrigação de abandoná-los sem perder a continuidade de si e os privilégios do mundo infantil. A mesma reflexão cabe para as seguintes fala de Clara em uma das sessões: 
"não gosto nem de pensar em ser adulta... Falar sobre ser adolescente parece que está enfiando um monte de agulhas em mim, tenho vontade de sair correndo, dói no peito." Nesses dados existem elementos que expressavam a intensidade das transformações psíquicas advindas com a eclosão do pubertário, movimento este que exigiu de Clara grande esforço psíquico para conciliar suas exigências pulsionais internas diante do ultimato do meio familiar e social: cresça!

\subsection{Uma adolescente em busca de apoio narcísico parental}

Em um das sessões clínicas, solicitou-se a Clara que desenhasse em uma linha um esboço do seu desenvolvimento. Durante a infância, referiu aos momentos felizes. Destacou seu aniversario, o nascimento da irmã e o parquinho da escola infantil, enfatizando ter sido este um dos momentos mais felizes da sua vida.

$\mathrm{Na}$ fase da latência, por volta de 9-10 anos, descreveu que começou a sua decadência. Fez um traço com o giz de cera preta dividindo a infância da entrada no período pubertário. Clara já havia dito que iniciou sua vida sexual aos 10 anos de idade. Percebeu-se que a jovem deveria voltar seus interesses para a vida social e intelectual, sublimando os impulsos sexuais eminentes do pré-pubertário. Todavia, não encontrou adultos de referência que lhe oferecessem limites e acolhimento sem contrarreagirem às suas solicitações pela via corporal, como apontou Marty (2006a). Em seguida relatou: "agora começa a parte negra da minha vida", desenhou uma boneca correndo atrás de outra. Disse ter sido nessa época em que se apaixonou pela professora. Observou-se que seu movimento em busca de apoio para conter a agressividade ameaçadora que o período pubertário trouxera apareceu logo após o período de latência, por meio de acting outs, como aponta Levisky (1998). Clara solicitou da professora, da escola e depois das namoradas algum sufrágio que a ajudasse a resistir a destrutividade da violência adolescente.

No segundo momento, fez o esboço de outra jovem com um cigarro nas mãos, apontando ter 12 anos nessa época. Referiu-se a esse período como seu declínio. Em seguida desenhou uma sequência de quatro meninas. A primeira parecia uma garotinha triste, a segunda tinha um dos olhos danificado, a terceira tinha os olhos e a boca ressaltados, e a quarta apareceu com um ponto de interrogação sobre a cabeça. Apontou que, nesse momento, não sabia mais definir as coisas, era seu momento de dúvida. $\mathrm{Na}$ sessão em que realizou o completamento de frases citou: "tempo mais feliz era minha eterna, expressiva infância, adolescência é a pior coisa que Deus me presenteou, e freqüentemente sinto confusão na minha mente". Vivência típica do momento em que o jovem busca por identificação para a construção da identidade.

Por fim, desenhou uma jovem e um rapaz de mãos dadas dentro de um coração, representando ela e o "namorido", que, segundo a descrição da jovem, era seu atual namorado e futuro marido. Indagou-se qual o significado desse desenho, respondeu: "aqui é o meu recomeço". Ressaltou que seu momento era diferente daquele desenhado para a mãe, no início da linha. No entanto, não era perceptível a diferença entre as jovens desenhadas. Seria esse um movimento de afastamento do objeto amoroso da infância, a mãe, para reinvestir em novos objetos amorosos e sexuais, por exemplo, a professora ou o "namorido"? As falas de Clara trazem a marca de alguém que buscou apoio ou referência em um outro (professora, Conselho Tutelar e, posteriormente, terapia), utilizando a linguagem dos atos no início da adolescência, movimento este que ilustra a busca de apoio narcísico parental apontada por Marty (2006b).

Baseando-se em Marty (2006b), foi possível compreender que Clara ao enfrentar seu estado de desamparo adolescente, defrontou-se com a ausência da mãe e do pai. Como não conseguiu interiorizar a função materna de proteção e continência, desenvolveu comportamentos transgressores para encontrar a reparação para aquilo que não recebeu destes. Assim, recorreu a outras figuras de referência para tentar suprir uma carência do início da vida no nível dos processos de simbolização que, segundo Marty (2006a), justificam os atos dos adolescentes para reparar o traumatismo por carência. A falta de uma figura continente, de autoridade e lei, também ressalta a falha na internalização da função parental.

\section{Considerações Finais}

O estudo demonstrou que Clara, enquanto sobrevivia à violência de ser empurrada para um lugar, reagindo à ruptura com o mundo infantil, buscou na figura da avó um apoio ou suporte que lhe oferecesse acolhimento e contenção da própria impulsividade que emergia com a eclosão da puberdade, suporte esse que a sua mãe não conseguia oferecer.

Uma análise mais detida sobre a função subjetiva e a transmissão transgeracional do lugar materno nessa família nos convocou a refletir sobre como foi transmitida a função materna entre as mulheres dessa família. Pareceu-nos que Clara encontra-se identificada com sua 
mãe e estaria vivenciando a chamada "Adulescente", palavra que é uma contração das palavras adulto ("adu") e adolescente ("lescente") e que expressa adultos que se identificam com adolescentes e jovens que, por sua vez, não conseguem renunciar às hesitações adolescentes e entrar na vida adulta (Kernier \& Cupa, 2012).

Utilizando uma linguagem corporal, Clara solicitou a reparação de uma falta que lhe foi negada desde a infância: o apoio narcísico. Em uma sequência de atos, após a entrada no período pubertário, a jovem buscou identificação e continência na professora, nas namoradas e na avó para estruturar a própria identidade e ultrapassar o período da adolescência. Pautando-se no que explica Marty (2006a), observaram-se as atuações dos adultos, no caso a avó e professora, que não suportando a destrutividade do processo de tornar-se adolescente de Clara, foram de contra reagirrverbal ou fisicamente, recusando-se também a assumir as responsabilidades que caberiam a cada um em seus lugares originais, como adultos de referência, de apoio, proteção, segurança e limites. Aspectos que nos levam a refletir sobre o despreparo das instituições família e escola em lidar e também sobreviver à fase de transformação que é a adolescência.

Quanto à avó, ainda se reconhecem essas figuras de forma romantizada, fadadas a oferecer conselhos e acalento aos netos. Esquece-se de que estas também são figuras humanas, com histórias inacabadas, com sentimentos dúbios e mal elaborados com relação aos próprios pais, como qualquer outro ser humano. Com este trabalho se almeja chamar a atenção para o lugar que essas figuras podem ocupar diante do desamparo adolescente ao acompanhar a violência que a fase da adolescência impulsiona nos netos.

Considerando o aspecto levantado quanto às novas configurações familiares e à presença expressiva dos idosos nas famílias brasileiras, sugere-se que estes também sejam lembrados ao se falar em pessoas que podem oferecer suporte e apoio ao adolescente, bem como na sua necessidade de também receberem apoio narcísico. Com resistências ou não, e mesmo com o término da terapia, Clara pôde vivenciar o apoio narcísico parental.

\section{Referências}

Berger, K. S. (2003). O desenvolvimento da pessoa da infância à terceira idade. Rio de Janeiro: LTC.

Conti, J. L. (2004). Adolescência feminina e violência familiar. (Tese de Doutorado não publicada). Instituto de
Psicopatologia e Psicologia Clínica, Universidade de Lion, Lion, França.

Debert, G. G. \& Simões, J. A. (2006). Envelhecimento e velhice na família contemporânea. Em Freitas, E. V. e cols. Tratado de geriatria e gerontologia. (2. ${ }^{2}$ ed.). (pp. 1368-1373). Rio de Janeiro: Guanabara Koogan.

Dias, C. M. S. B. (1994). A importância dos avós no contexto familiar. Psicologia: Teoria e Pesquisa, 10(1), 31-40.

Emmanuelli, M. (2011). As saídas para o trabalho psíquico da adolescência. Psicologia em Estudo, 16(1), 51-60.

Freud, S. (1974). Sexualidade feminina. Em Edição Standard Brasileira das Obras Psicológicas Completas de Sigmund Freud. (Vol. 21, pp. 255-279). Rio de Janeiro: Imago. (Trabalho original publicado em 1931).

Freud, S. (1976). Algumas consequências psíquicas da distinção anatômica entre os sexos. Em Edição Standard Brasileira das Obras Psicológicas Completas de Sigmund Freud. (Vol. 19, pp. 301-320). Rio de Janeiro: Imago. (Trabalho original publicado em 1925).

Freud, S. (2001). Três ensaios sobre a sexualidade. Em: Edição Eletrônica Brasileira das Obras psicológicas completas de Sigmund Freud. 2.0. CD- Rom. ( $2^{\mathrm{a}}$ ed.). Rio de Janeiro: Imago. (Trabalho original publicado em 1905).

Goldfarb, D. C., Lopes, R. G. C. (2006). Avosidade: a família e a transmissão psíquica entre gerações. Em: Freitas, E. V. e cols. Tratado de geriatria e gerontologia. (pp.1374-1382). Rio de Janeiro: Guanabara Koogan.

Gomes, I. C. \& Zanetti, S. A. S. (2009). Transmissão psíquica transgeracional e construção de subjetividade: relato de uma psicoterapia psicanalítica vincular. Psicologia USP, 20(1), 93-108.

Kernier, N. de, \& Cupa, D. (2012). Adolescência: muda psíquica à procura de continentes. Agora: Estudos em Teoria Psicanalitica, 15(spe),453-467.

Lacan, J. (1973/2003). O aturdido. Em: Outros escritos (pp. 449-497). Rio de Janeiro: Zahar.

Lachmann, P. J. (2011). The grandmother effect. Gerontology, 57, $375-377$.

Levisky, D. L. (1998). O processo de identificação do adolescente à luz da psicanálise contemporânea. 
Em Levisky, D. L. Adolescência: reflexões psicanalíticas. (3a. ed.). (pp. 85-143). São Paulo: Casa do Psicólogo.

Lopes, E. S. L., Neri, A. L. \& Park, M. B. (2005). Ser avós ou ser pais: os papéis dos avós na sociedade contemporânea. Textos sobre Envelhecimento, 8(2), 239-253.

Marcos, C. (2011). Mãe e filha: da devastação e do amor. Tempo psicanal., 43(2), 269-284.

Marty, F. (2006a). Adolescência, violência e sociedade. Agora, 9(1), 119-131.

Marty, F. (2006b). L'adolescence dans l'histoire de la psychanalyse. L'évolution psychiatrique, 71, 247-258.

Marty, F. (2013). Soutiens narcisiques à l'adolescence. Trabalho apresentado no I Colóquio Internacional sobre cultura adolescentes, subjetividades, contextos y debates actuales. Buenos Aires, Argentina. Disponível em: http://coloquio.sociedadescomplejas.org. Acesso em 15 out. 2012.

Marty, F., Cardoso, M. R. (2008). Destinos da adolescência. Rio de Janeiro: 7letras.

Molinier, P. (2004). O ódio e o amor, caixa preta do feminismo? Uma critica da ética do devotamento. Psicologia em Revista, 10 (16), 227-242.

Oliveira, M. R. (2011). As relações intergeracionais e a participação dos avós na família dos filhos. (Tese de doutorado não publicada). Instituto de Psicologia, Universidade de Brasília, Brasília, Brasil.
Pedrosa, A. S. (2006). Homens idosos avôs: significado dos netos para o cotidiano. (Dissertação de Mestrado não publicada). Programa de Gerontologia, Universidade Católica de São Paulo, São Paulo, Brasil.

Pereira, A. C. A. (2005). A teoria psicossocial de Erickson e a construção da identidade. $O$ adolescente em desenvolvimento. São Paulo: Harbra.

Rodrigues, A. P. \& Justo, J. S. (2009). A ressignificação da feminilidade na terceira idade. Estud. interdiscipl. envelhec., 14(2), 169-186.

Sarti, C., A. (2008). Famílias enredadas. Em Acosta, A. R, Vitale, A. F. (Eds.). Família, redes, laços e politicas públicas. (4a ed.). (pp. 21- 36). PUC/SP: Cortez.

Savietto, B. B., Cardoso, M. R. (2006) Adolescência: ato e atualidade. Revista Mal-estar e Subjetividade, 6(1), 15-43.

Sudbrack, M. F. O. e cols. (2003). O adolescente e as drogas no contexto da justiça. Brasília: Plano Piloto Editora.

Vitale, M. A. F. (2008). Avós: velhas e novas figuras da família contemporânea. In: Acosta, A. R. \& Vitale, A. F. (Eds). Família, redes, laços e políticas públicas (4a. ed.). (pp. 93-105). PUC/SP: Cortez.

Recebido em: 18/12/2012

Reformulado em: 03/10/2013

Segunda reformulação em: 28/10/2013

Aprovado em: 12/11/2013

Sobre as autoras:

Kelly Lins Beserra Pinto é graduada em psicologia pela UCB e atua como psicóloga organizacional no Hospital Santa Luzia-Brasília

Alessandra da Rocha Arrais é doutora em Psicologia pela Universidade de Brasília, psicóloga clínica, psicóloga hospitalar da Secretaria de Estado de Saúde do Distrito Federal (SES-DF), docente do curso de Psicologia, do mestrado em gerontologia da Universidade Católica de Brasília (UCB) e do mestrado profissionalizante em Saúde da Mulher e do Idoso da FEPECS.

Katia Cristina Tarouquella Rodrigues Brasil é doutora em psicologia pela Universidade de Brasília; psicóloga clínica, docente do curso de psicologia e do Programa de Doutorado e Mestrado em Educação da Universidade Católica de Brasília (UCB). 
